\title{
THE DEGENERATION OF BRAIN THROMBOPLASTIN IN THE PRESENCE OF NORMAL SERUM
}

\author{
BY \\ C. G. BERRY \\ From St. James' Hospital, Balham, London, S.W.12* \\ (RECEIVED FOR PUBLICATION NOVEMBER 14, 1956)
}

It has long been known that the " prothrombin"
time of a specimen of plasma to which has been
added a brain extract thromboplastin depends on the
presence of other factors in addition to prothrombin. Biggs, Douglas, and Macfarlane (1953) have demonstrated that both factor $\mathrm{V}$ and factor VII take part in a preliminary reaction with the brain extract to produce an activated thromboplastin. Hardisty (1955) believes that the amount of thromboplastin generated depends on the available factor $\mathrm{V}$, whereas its rate of generation is controlled by factor VII. Experiments described by these workers have shown that mixtures produced by incubating brain extract with factor V, factor VII, and calcium have a thromboplastin content which gradually increases in titre until a maximum is reached, after which there is a rapid deterioration. A similar course of events is observed in the thromboplastin generation test (Biggs and Douglas, 1953) following the incubation of platelets, Christmas factor, antihaemophilic globulin, factors V and VII, and calcium. In all of these tests attention has been focused on the generation of thromboplastin, and its subsequent disappearance seems to have been ignored. The experiments described in the present paper were designed to observe the fate of brain thromboplastin after its activation by normal serum, and the results of this work are discussed.

\section{Methods}

Blood $10 \mathrm{ml}$., was collected into siliconed centrifuge tubes, citrated $(0.1 \mathrm{ml}$. citrate $/ 1 \mathrm{ml}$. blood) and immediately centrifuged at 1,500 r.p.m. for five minutes. The plasma was removed and centrifuged for a further 15 minutes at 3,000 r.p.m. The resulting platelet-free plasma was diluted with an equal volume of saline and then placed in melting ice. until ready for use. This $50 \%$ dilution of platelet-free plasma was used as the substrate plasma in the test.

A further $5 \mathrm{ml}$. of blood was collected and allowed to clot. The clotted blood remained in a water-bath at $37^{\circ} \mathrm{C}$. for a minimum of two hours and the serum then collected for use in the test.

\footnotetext{
*Present address: The Pathology Laboratory, Kano, Northern Nigeria, B.W. Africa.
}

Brain thromboplastin was used, prepared as described? by Biggs and Macfarlane (1953). This thromboplastin $\vec{\circ}$ was diluted with saline to give a prothrombin time of $\triangle$ about 20 seconds with the substrate plasma.

Aluminium hydroxide suspension ("alumina ") was prepared by the method described by Biggs and Macfar-음 lane (1953).

M/40 calcium chloride was used to recalcify the $\vec{z}$ substrate plasma.

In a rack in the $37^{\circ} \mathrm{C}$. water-bath were placed 16 tubes in readiness for the clotting times which are to be performed. Two further tubes contained the thrombo- $\frac{\mathbb{D}}{-}$ plastin mixtures. Into each of these was pipetted $0.5 \mathrm{ml}$. $\overrightarrow{0}$ of calcium chloride. Then to one was added $0.5 \mathrm{ml}$. \&f or serum and to the other (the control) $0.5 \mathrm{ml}$. of salise. To each of these was then added $1 \mathrm{ml}$. of the diluted bra角 thromboplastin and a stop-watch was started.

A specimen from each of these thromboplastin mixtures was immediately used to perform a clotting time, adding $0.2 \mathrm{ml}$. of the mixture to $0.1 \mathrm{ml}$. of the substrate plasma, $\frac{2}{\mathbb{2}}$ and the clotting times were recorded. This was repeated at intervals of $1,3,5,10,15,30$, and 60 minutes after preparation of the two mixtures.

It was found to be important to transfer the $0.1 \mathrm{ml}$. of substrate plasma from the tube in melting ice to the tube in the water-bath no more than five minutes before each estimation. If the plasma remained at $37^{\circ} \mathrm{C}$. for 0 longer than this there was a false prolongation of the $\frac{0}{3}$ clotting time using either of the thromboplastin mixtures.

These experiments were performed using (a) specimens $\delta$ of fresh normal serum, $(b)$ normal serum up to three weeks old, $(c)$ thromboplastin mixtures prepared at $0^{\circ} \mathrm{C}$. 0 and kept in melting ice during the test, $(d)$ varying dilutions of serum, $(e)$ serum heated to $60^{\circ}$ for five $\frac{7}{0}$ minutes and $100^{\circ}$ for one minute, $(f)$ serum adsorbed with either "alumina" or barium sulphate, and N $(g)$ serum from patients receiving 2-phenylindane 1: 3-dione ("dindevan").

\section{Results}

The control saline-thromboplastin-calcium mixture gave a constant clotting time of about 20 seconds $\mathbb{\Phi}$ throughout the one-hour period of the test, nor? indeed was there any significant variation in the $\frac{T}{0}$ readings when the test was prolonged over a longer $\overrightarrow{\mathbb{D}}$ period (up to four hours). 
Using serum in place of the saline, however, results in an immediate shortening of the clotting time of the substrate plasma to as low as 5 seconds. Following this there is a rapid deterioration of the thromboplastin mixture, and the clotting times very soon exceed those produced by the control specimen (Fig. 1). This degeneration is most rapid imme-

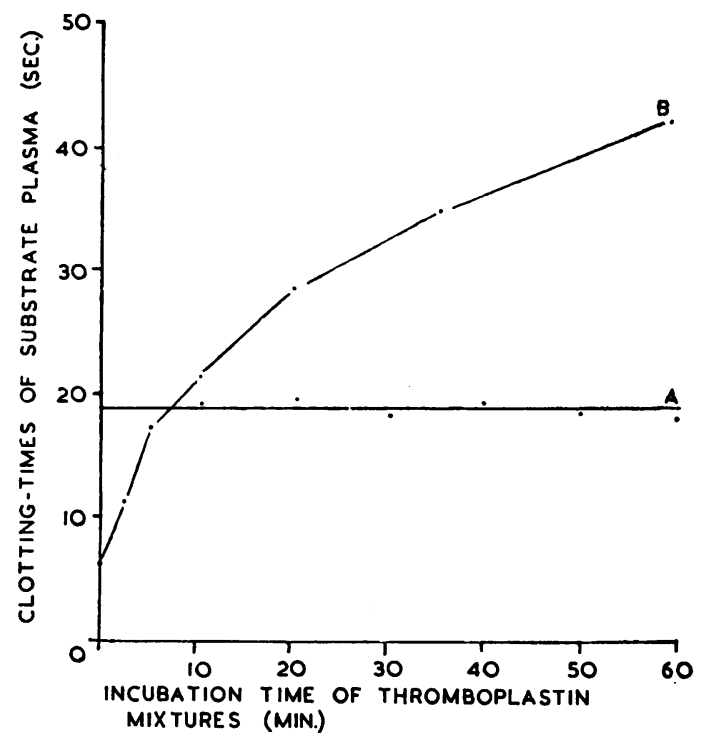

FIG. 1.-Clotting times of substrate plasma using (A) a salinecalcium-thromboplastin mixture, and (B) a serum-calciumthromboplastin mixture at different times after preparation of the mixtures (at " 0 " on the graph).

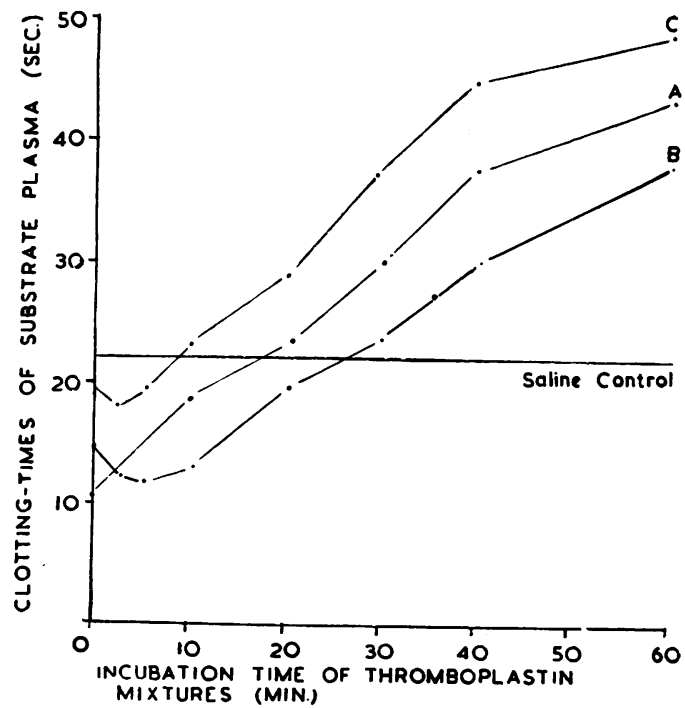

Fig. 2.-Effect of using (A) fresh serum, (B) serum one week old, and (C) serum three weeks old, for the preparation of the thromboplastin mixtures. diately after preparation of the thromboplastin mixture when its potency is greatest; as the potency falls so too does the rate of thromboplastin degeneration.

Similar results are obtained when older specimens of serum are used. With increasing age of serum there is a short delay of up to five minutes before

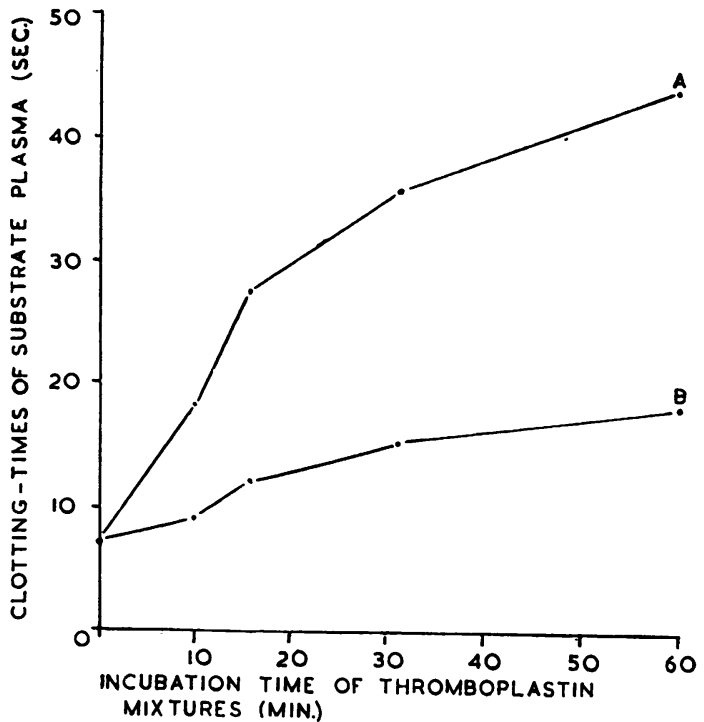

FIG. 3.-Clotting times of substrate plasma using (A) thromboplastin mixture prepared and incubated at $37^{\circ} \mathrm{C}$., and (B) thromboplastin mixture prepared and incubated at $0^{\circ} \mathrm{C}$.

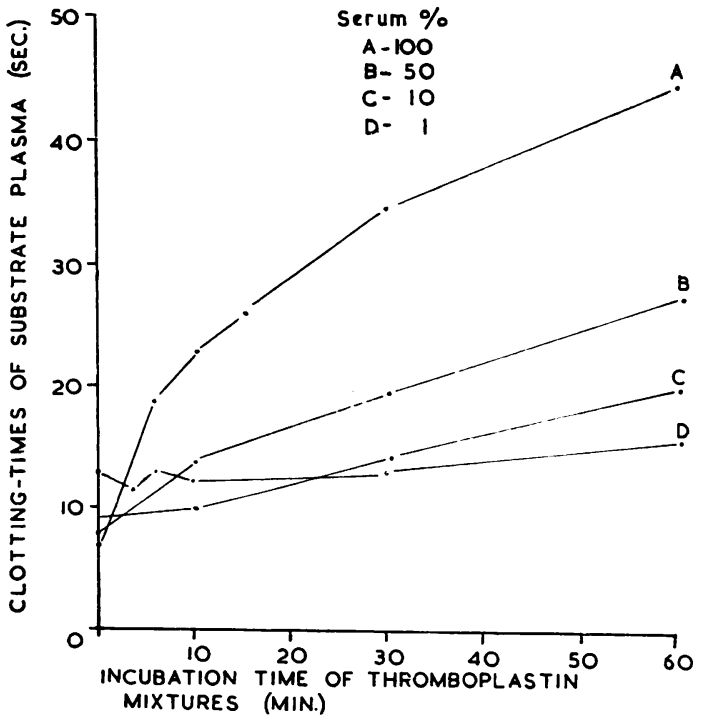

FIG. 4.-Graph showing the effect of using different dilutions of serum for the preparation of the thromboplastin mixtures. 
the thromboplastin mixture reaches its maximum potency. The rate of degeneration is unaltered, however (Fig. 2).

When the thromboplastin mixture is kept at $0^{\circ} \mathrm{C}$. during the test the increased potency is no less, but it is retained for a longer period (Fig. 3). Thus the rate of thromboplastin degeneration is reduced at lower temperatures.

Following these observations it was decided to investigate the effect of using varying dilutions of serum for the preparation of the thromboplastin mixtures. A series of tests was performed using $100 \%, 50 \%, 10 \%$, and $1 \%$ dilutions of serum. With increasing di ution the resulting activated thromboplastin was found to be less potent; the more concentrated sera produced the more powerful thromboplastin. The difference in clotting times produced by the $100 \%$ serum-thromboplastin and the $1 \%$ serum-thromboplastin was never greater than 6 seconds, however. The rate of thromboplastin degeneration varied with serum dilution, being greatest in those mixtures prepared from the more concentrated specimens of serum (Fig. 4).

Serum heated to $60^{\circ} \mathrm{C}$. for five minutes loses its ability to activate brain thromboplastin, but is still able to bring about its rapid degeneration (Fig. 5). Heating to $100^{\circ} \mathrm{C}$. for one minute denatures the proteins and coagulates the serum. Fluid expressed

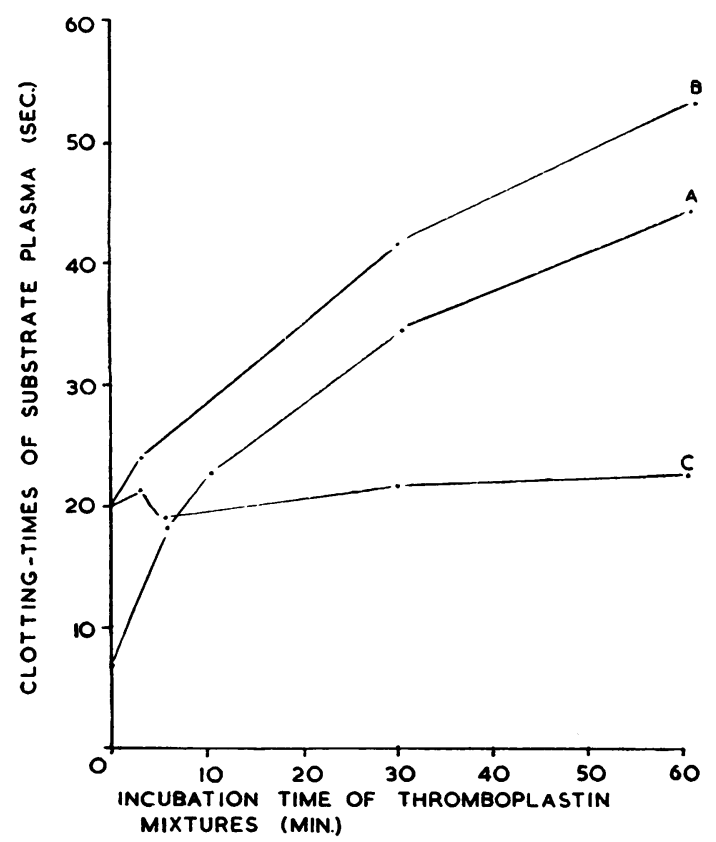

FIG. 5.-Graph showing the effect of using (A) untreated serum, (B) serum heated to $60^{\circ} \mathrm{C}$. for five minutes, and (C) serum heated to $100^{\circ} \mathrm{C}$. for one minute, for the preparation of the thromboplastin mixture.

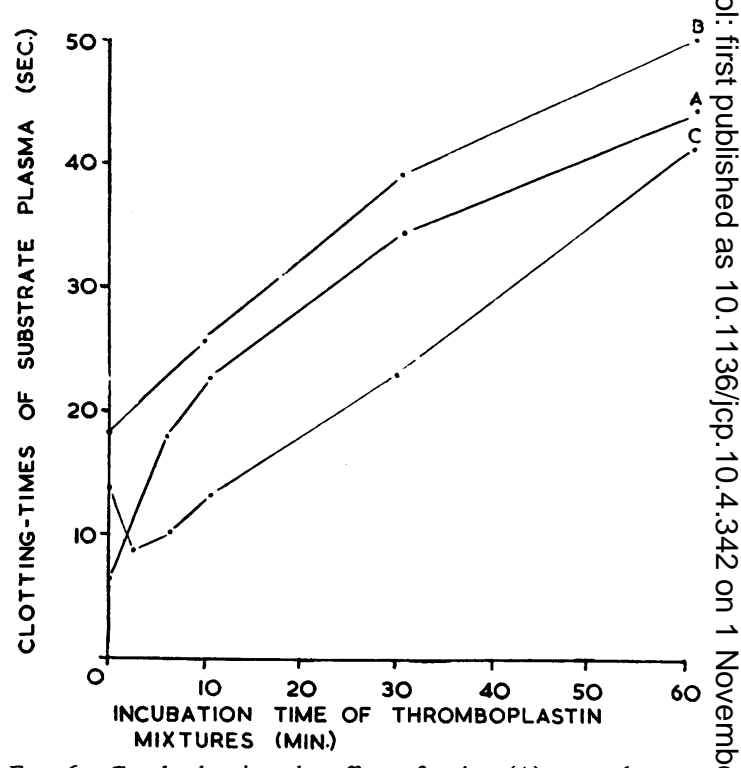

FIG. 6.-Graph showing the effect of using (A) normal serum,

(B) normal serum adsorbed with either $\mathrm{BaSO}_{4}$ or alumina, and

(C) serum from a patient treated with "dindevan."

from this coagulum and incubated with brân. extract is no longer able to destroy the thromberplastin.

Serum adsorbed with either alumina or bariumo sulphate (at $37^{\circ} \mathrm{C}$. for 15 minutes) has the sameo effect on brain extract as serum which has been $\mathbb{Q}$ heated to $60^{\circ}$ C.; the rate of thromboplastin $\overrightarrow{\vec{A}}$ degeneration remains unchanged although there is 3 no activation (Fig. 6).

Finally, serum from patients receiving " dinde-o․ van " was used. In such cases the clotting time of the patients' uncitrated blood is prolonged, and to? cnsure complete prothrombin consumption and thrombin utilization these specimens were allowed to stand in the $37^{\circ}$ water-bath for a minimum of four hours before the serum was separated. Brain thromboplastin subjected to such specimens of serum showed a delay of up to five minutes before maximum potency was reached, but the rate of degeneration remained unchanged (Fig. 6).

\section{Discussion}

Specimens of serum used in these investigations ${ }^{\mathrm{c}}$ had been kept for a minimum of two hours after coagulation in a water-bath at $37^{\circ} \mathrm{C}$. After thise time there remained in the serum no prothrombines and no thrombin to complicate the subsequent tests:?

The control experiments, using saline in place of serum, showed no potentiation and no deterioration of the brain extract over a period of several hours? Serum, however, brought about an immediate 
increase in thromboplastin activity, and further tests investigating the effects of storage, adsorption, and heating to $60^{\circ} \mathrm{C}$. suggested that factor VII must be responsible for this activation of brain extract. These were the expected results and agreed with the findings of other workers.

Following this increase in potency thromboplastin deteriorates rapidly, and it appeared that factor VII converted the brain extract into a more potent but labile form. Experiments with the thromboplastin mixture in melting ice showed that it was no more stable at lower temperatures, however, although the degeneration continued at a slower rate. This loss of thromboplastin activity, irrespective of the temperature of the specimen, suggested that there might be a second factor in the serum, an antithromboplastin. This hypothesis appeared to be confirmed by the next series of tests, investigating the effect of dilution, heat, and adsorption on serum. The more dilute the serum the slower was the rate of thromboplastin degeneration. Serum heated to $100^{\circ} \mathrm{C}$. for one minute lost its ability both to potentiate and to destroy thromboplastin. When heated to $60^{\circ} \mathrm{C}$., however, the antithromboplastin effect remained. Likewise serum adsorbed with either barium sulphate or alumina retained the antithromboplastin effect, even though the initial activation of the brain extract was abolished. The serum of patients receiving "dindevan" showed no loss of antithromboplastin activity.

From these results it was concluded that brain extract thromboplastin, which is stable at $37^{\circ} \mathrm{C}$. in a saline suspension, is actively destroyed by a factor which is present in normal serum. This factor, which may be called an antithromboplastin, is unaffected by heating to $60^{\circ} \mathrm{C}$., neither is it removed by adsorption with barium sulphate or alumina, but it is destroyed when briefly subjected to a temperature of $100^{\circ} \mathrm{C}$. It is present in normal titre in the serum of patients who are being treated with "dindevan." The antithromboplastin appears to be equally active against activated or inactivated brain extracts. It may be that this factor plays a part in the control of intravascular thrombosis in vivo by removing from the blood excess tissue products liberated after trauma.

\section{Summary}

Experiments investigating the effect of normal serum on brain thromboplastin are described. Following an immediate potentiation of the thromboplastin there is a rapid deterioration, and it is suggested that this is brought about by the presence in the serum of an antithromboplastin. This antithromboplastin can withstand a temperature of $60^{\circ} \mathrm{C}$., but is destroyed by subjecting to a temperature of $100^{\circ} \mathrm{C}$. for one minute. It is not adsorbed on either barium sulphate or aluminium hydroxide suspensions. It is unaffected by treatment with " dindevan."

It is postulated that antithromboplastin is a normal constituent of the blood, limiting thrombosis to the site of injury by removing excess extrinsic thromboplastin.

I wish to thank the surgical and nursing staff of St. James' Hospital for their co-operation during these investigations, and especially Mr. N. C. Tanner and Mr. A. M. Desmond under whose care the patients were admitted. I would also like to thank Dr. G. T. Allen for his advice and assistance and for reading the manuscript.

\section{REFERENCES}

Biggs, R., and Douglas, A. S. (1953). J. clin. Path., 6, 23. 554. and Macfarlane, R. G. (1953). J. Physiol. (Lond.), 122,

and Macfarlane, R. G. (1953). Human Blood Coagulation and

its Disorders. Blackwell, Oxford.

Hardisty, R. M. (1955). Brit. J. Haemat., 1, 323. 